\title{
The Effects of Make and Take Fees in Experimental Markets
}

\author{
Vince Bourke and David Porter \\ Economic Science Institute \\ Chapman University
}

\section{Introduction \& Literature Review}

The prevailing trading payment mechanism used by all registered U.S. equity exchanges is make and take fees. The Formally, the Securities and Exchange Commission (SEC) offers the following description of make and take fees: "non-marketable, resting orders that offer (make) liquidity at a particular price receive a liquidity rebate if they are executed, while incoming orders that execute against (take) the liquidity of resting orders are charged an access fee" (SEC 2010). Throughout this paper, we refer to the liquidity rebate as the make fee/rebate and the access fee as the take fee ${ }^{1}$. Each transaction requires at least two participants - a market maker who enters the market first to post a non-marketable order and a market taker who subsequently hits the market maker's posted order. Upon execution, the market maker receives the make rebate and the market taker is charged the take fee. Market making behavior is beneficial to an equity exchange because it creates opportunities for other participants to trade on that exchange. Conversely, market taking behavior removes opportunities for others to trade so market takers incur the take fee, which is generally greater in absolute value than the make rebate. Thus, the difference between the two represents revenue for the exchange for facilitating the order. This difference is referred to as the net, or total fee.

\footnotetext{
${ }^{1}$ Despite our stylistic conventions, Cardella et al. (2014) provided an example of an exchange running a promotional period where the take fee was negative - meaning market takers received a rebate from the exchange. Generally speaking, however, the make rebate and the take fee are accurate descriptions.
} 
Make and take fees have existed in some form since the late 1990s. When the SEC adopted their Order Execution Guidelines², Electronic Communication Networks (ECNs) responded by requiring participants to pay to access order flow. The first recorded exchange to use make and take fees, the Island ECN, introduced them in 1997. Their trading volume market share of NASDAQ-listed shares increased from three percent in 1997 to thirteen percent in 1999 (Cardella et al. 2014). In 2007, the SEC implemented the Regulation National Market System (Reg. NMS). The idea was to have a market composed of multiple trading venues all linked together via rules over access and trade priority (O’Hara 2015). This created competition between exchanges for trading volume which led to widespread adoption of the make and take fee structure. The NYSE's fee structure is described in their 21-page 'Schedule of Fees and Charges for Exchange Services'. In this fee schedule, more frequent traders receive more favorable considerations. For example, NYSE defines a "Tier 1 " trader as one who "provide[s] liquidity...an average daily share volume per month of $0.70 \%$ or more of the U.S. CADV (consolidated average daily volume)." A Tier 1 trader will receive a make rebate of $23-30$ cents per hundred shares and is assessed a take fee of $28-30$ cents per hundred shares, depending on the tape on which the share is listed. The several tiers beneath Tier 1 have less favorable considerations. At the "Basic Rates" level, the make rebate is fixed at 20 cents per hundred shares and the take fee is fixed at 30 cents per hundred shares independent of the tape. These fees and rebates are assigned irrespective of the price of the stock. From 1/2/15 through 11/30/15, 272 billion shares traded on the NYSE. Even if we assume that every trader received the most favorable take fee considerations, market takers transferred approximately 761 million dollars to market makers and exchanges during this eleven-month period.

The fee structure has seen more widespread attention in the past few years - most notably when Michael Lewis questioned the practice of paying market makers to inject liquidity into a

\footnotetext{
${ }^{2}$ Downloadable at https://www.sec.gov/answers/bestex.htm
} 
system in his book Flash Boys. In a June 17, 2014 hearing of the Senate Permanent Subcommittee on Investigations, NYSE president Thomas Farley said the exchange is "seeking support for the elimination of maker-taker (fees)." (Lyon 2014). Critics of the make and take fee structure point to the misaligned incentives between brokers and their clients. Angel et al. (2011) published a critique of the make and take fee structure in their report on trends in equity trading since 2000 . They claim that make and take fees have "distorted order routing decisions, aggravated agency problems among brokers and their clients, unleveled the playing field among dealers and exchange trading systems, produced fraudulent trades, and produced quoted spreads that do not represent actual trading costs." In a recent memorandum, the SEC proposed a number of changes to the implementation of make or take fees, including requiring fees and rebates to be passed back to the customer from the broker and requiring access (take) fees to be included within publicly available quotes. Both of these measures would mitigate the intrinsic agency issues that arise when dealers or brokers are incentivized to search for rebates without regard to execution quality. The SEC addresses the issue of eliminating make and take fees but remains non-committal. On the one hand, they claim that elimination would address agency concerns and market complexity. On the other hand, they believe that elimination would widen spreads and undermine the ability of the exchanges to compete with off-exchange "dark pools" (private venues for trading securities). The results from our experiments show that the make and take fee structure does not narrow spreads, thus eliminating the argument in favor of such fees. Despite the considerable ongoing discussion, it appears that make or take fees will remain the prevailing fee structure for the immediate future.

In this paper, we report the results of the first series of experiments designed to capture the effects of fee structures on individuals who proxy for non-algorithmic brokers by considering three established market quality indicators - efficiency, bid-ask spread, and book depth. We exogenously impose trading fees in a double auction environment, an institution commonly used to model stock 
markets. Our design includes two treatments - a trading fee treatment in which both sides of a transaction are assessed a trading fee upon order execution and a make and take treatment in which market makers receive a rebate and market takers are assessed a fee upon order execution and a baseline case with no fees assessed to either side of a transaction. We will consider each indicator in turn to review the relevant literature and develop our hypotheses.

Bid-Ask Spread: Colliard and Foucault (2012) develop a theoretical microstructure model of exchange under a make and take fee structure and show that the raw (quoted) bid-ask spread can increase or decrease when the net fee is reduced, depending on whether the reduction in net fee is achieved by lowering the make fee (this causes a decrease) or by lowering the take fee (this causes an increase). Two recent papers have analyzed large data sets to document the effects of implementing a make and take fee structure on the bid-ask spread. Malinova and Park (2013) examined a proprietary data set from a 2005 on the Toronto Stock Exchange (TSX) and found that under a trial make and take fee regime, the quoted spreads did not change. Kalcheva et al. (2014) analyzed a larger sample of all registered equity exchanges from 2008 - 2010 and were unable to document a significant relationship between bid-ask spread and make and take fees. In a 2011 paper, Harris develops a theoretical model and uses empirical data to conclude that make and take fees result in narrower bid ask spreads. The SEC claims, in their October 2015 “Memorandum: Maker-Taker Fees on Equity Exchanges" that "make and take fee structures artificially narrow displayed spreads because the liquidity rebate effectively subsidizes the posting of liquidity." This assertion is problematic because it fails to consider the magnitude of the take fee in relation to the make rebate. We expect spreads will change in three ways during our sessions:

1. Spreads will widen in the presence of trading fees or make and take fees relative to no fees.

2. Spreads will be equal in the presence of trading fees and make and take fees. 
3. Spreads will widen with an increase in the level of net fee within each fee structure.

The following example will illustrate. Assume a hypothetical buyer $i \in I$ has a valuation of $v_{i}$ and a seller $j \in J$ has a cost of $c_{j}$ for one unit of an indivisible good. In the absence of fees, the buyer and seller can profitably transact at prices in the interval $\left[c_{j}, v_{i}\right]$. In the presence of fees, less surplus can be allocated and spreads widen. To see this, suppose an exchange offers a make rebate of $m$ and assesses a take fee of $t$, where $|t|>|m|$ and $t-m=f$, where $f$ is the net fee (this is positive from the exchange's perspective and negative from the trader's perspective). The buyer enters the market first and places a limit order. She will be willing to post a price greater than her valuation, since she will receive the make rebate of $m$ upon execution. Thus, she will post a price in the interval $\left[0, v_{i}+m\right]$. The seller then enters the market and observes the buyers' limit order. To complete a trade, she must place a market order. However, she is only willing to post a price greater than her cost, since she will incur the take fee of $-t$ upon execution. Thus, she will post a price in the interval $\left[c_{j}+t, \infty\right]$. When $c_{j}=v_{i}$, this implies that the spread will never be less than $\left(c_{j}+t\right)-$ $\left(v_{i}+m\right)=t-m$. Suppose instead that an exchange charges trading fees to both sides of a transaction equal to $\frac{1}{2} f$. In this case, the buyer will post a price in the interval $\left[0, v_{i}-\frac{1}{2} f\right]$ and a seller will post a price in the interval $\left[c_{j}+\frac{1}{2} f, \infty\right]$. When $c_{j}=v_{i}$ this implies that the spread will never be less than $\left(c_{j}+\frac{1}{2} f\right)-\left(v_{i}-\frac{1}{2} f\right)=f=t-m$, which is equal to the implied minimum spread in the presence of make and take fees. It is also apparent from this example that the bid-ask spread should increase with an increase in the level of net fee.

Efficiency: Battalio et al. (2013) analyzed a proprietary data set and the NYSE's Trade and Quote data to demonstrate the negative relationship between limit order execution quality and the relative level of liquidity fees. In a different paper, Battalio et al. (2011) gauge the influence of take fees on trading costs using a data set from an options trading firm. Their evidence suggests a 
liquidity-demanding trader is better off under a pay-for-order-flow (PFOF) model than a make and take model.

However, our discussion of efficiency primarily considers the effects of fee structures on individual investor efficiency. Make and take fees, like trading fees, are assigned based on quantity traded without regard to share price. Though the aggregate effect on efficiency is zero, traders who trade lower-priced stocks lose a greater percentage of possible surplus than those who trader higher-priced stocks. In Table 1, we illustrate the costs of fees incurred under a make and take schedule.

\begin{tabular}{|c|c|c|c|c|}
\hline Share Price & Quantity & Trade Amount & Take Fee & $\%$ Fee \\
\hline$\$ \mathbf{1 . 5 0}$ & 100 & $\$ 150.00$ & $\$ 0.30$ & $0.002 \%$ \\
\hline $\mathbf{\$ 1 0 . 0 0}$ & 100 & $\$ 1000.00$ & $\$ 0.30$ & $0.0003 \%$ \\
\hline $\mathbf{\$ 5 0 . 0 0}$ & 100 & $\$ 5000.00$ & $\$ 0.30$ & $0.00006 \%$ \\
\hline
\end{tabular}

In Section III, we demonstrate this effect experimentally by considering gross efficiency (unadjusted for the effects of fees) and the level of net fee relative to the predicted price. We also examine net efficiency (adjusted for the effects of fees) to determine if the presence of a fee structure affects the surplus that subjects are able to extract from the trading environment. We hypothesize efficiency will change in the following ways:

1. Efficiency will be lower in the presence of trading fees or make and take fees relative to no fees. Further, efficiency loss increases with the level of net fee.

2. Efficiency will be equal in the presence of trading fees and make and take fees.

3. Efficiency will be lower in periods of low equilibrium price, regardless of quantity traded.

Book Depth: Foucault et al. (2013) develop a theoretical model of profit maximization and market monitoring intensity. In their model, the aggregate monitoring level decreases in monitoring costs and in the fee charged. We use placing orders and the associated book depth generated from these orders as a suitable proxy for aggregate monitoring level because placing orders in our design is 
costless. Their conclusion, restated, is the aggregate monitoring level (book depth) increases in monitoring benefits. Monitoring benefits are tangible whether a fee schedule is present or not, but we expect an increase in book depth when traders are further incentivized to monitor the market to earn make rebates. They show a negative relationship between book depth and the magnitude of fees. We expect book depth will change in the following ways:

1. Book depth will increase in the presence of make and take fees relative to trading fees and no fees because of the incentives (rebates) to monitor the market more closely.

2. Book depth will increase as incentives to monitor the market increase (higher take fees and make rebates).

The paper proceeds as follows. Section II describes the experimental design, including a detailed description of the auction mechanism and methodology used in calculating our market quality indicators. Section III contains results and a discussion. Section IV concludes and offers some interesting directions for future extensions to our research.

\section{Experimental Design \& Auction Mechanism}

Sixteen experimental sessions were conducted at a major North American university. In each eight-subject session, four subjects were assigned to the role of buyer and four subjects were assigned to the role of seller. Subjects were seated at computer terminals in a laboratory and were given role-specific instructions ${ }^{3}$. The instructions were self-paced and required subjects to complete examples of the tasks that they would perform during the experimental trading periods 4 . Subjects earned an average of $\$ 30.60$ for a 1.5 hour session (including a $\$ 7.00$ show-up bonus). At the end of the session, subjects completed a short questionnaire that asked them to describe the strategies that they used within and between market periods.

\footnotetext{
${ }^{3}$ Refer to Appendix B for a copy of the subject instructions.

${ }^{4}$ Refer to Appendix C for a diagram of the user interface.
} 
We use a nonstationary double auction environment in to the baseline model from Smith et al. (1992) primarily because its structural features reduce potential price discovery which makes inferences regarding the bid-ask spread robust. Further, the double auction is used to model stock markets given its operational simplicity, efficiency, and its capacity to respond quickly to changing market conditions (Gjerstad and Dickhaut 1998). In each period in our experimental environment, a value for an random variable $x$ was drawn uniformly from $[-50,-40,-30, \ldots, 50]$.

Buyers had resale values randomly drawn from the following inverse demand function:

$$
D(p)=\left\{\begin{aligned}
140+x, & 0<q \leq 5 \\
130+x, & 5<q \leq 10 \\
120+x, & 10<q \leq 15 \\
110+x, & 15<q \leq 20 \text { where } x \text { is drawn from unif }(-50,50) \\
100+x, & 20<q \leq 25 \\
90+x, & 25<q \leq 30 \\
80+x, & 30<q \leq 35
\end{aligned}\right.
$$

Similarly, sellers had costs randomly drawn from the following inverse supply function.

$$
S(p)=\left\{\begin{aligned}
60+x, & 0<q \leq 5 \\
70+x, & 5<q \leq 10 \\
80+x, & 10<q \leq 15 \\
90+x, & 15<q \leq 20 \text { where } x \text { is drawn from unif }(-50,50) . \\
100+x, & 20<q \leq 25 \\
110+x, & 25<q \leq 30 \\
120+x, & 30<q \leq 35
\end{aligned}\right.
$$

Thus, buyer $i \in I$ has a vector of induced values $v_{i}=\left(v_{i}^{1}, v_{i}^{2}, \ldots, v_{i}^{n}\right)$ that are monotonically decreasing such that $v_{i}^{n}<v_{i}^{n-1}$. Similarly, seller $j \in J$ has a vector of induced costs $c_{i}=$ $\left(c_{i}^{1}, c_{i}^{2}, \ldots, c_{i}^{n}\right)$ that are monotonically increasing such that $c_{i}^{n}>c_{i}^{n-1}$.

In our treatments with no fees (B), the profit for trade $n_{n} \in\left(n_{1}, n_{2}, \ldots, n_{N}\right)$ that matches a buyer $i$ and seller $j$ is:

$$
\pi_{i}=v_{i}^{n}-p_{n} \quad \pi_{j}=p_{n}-c_{j}^{n}
$$

In our treatments with trading fees (TF), the profit for trade $n_{n} \in\left(n_{1}, n_{2}, \ldots, n_{N}\right)$ that matches a buyer $i$ and seller $j$ is: 


$$
\pi_{i}=v_{i}^{n}-p_{n}-\frac{1}{2} f \quad \pi_{j}=p_{n}-c_{j}^{n}-\frac{1}{2} f
$$

In our treatments with make and take fees (MT), the profit for trade $n_{n} \in\left(n_{1}, n_{2}, \ldots, n_{N}\right)$ that matches a market making buyer $i$ and market taking seller $j$ is:

$$
\pi_{i}=v_{i}^{n}-p_{n}+m \quad \pi_{j}=p_{n}-c_{j}^{n}-t
$$

Figure 1 illustrates the normalized $(x=0)$ structure of supply and demand:

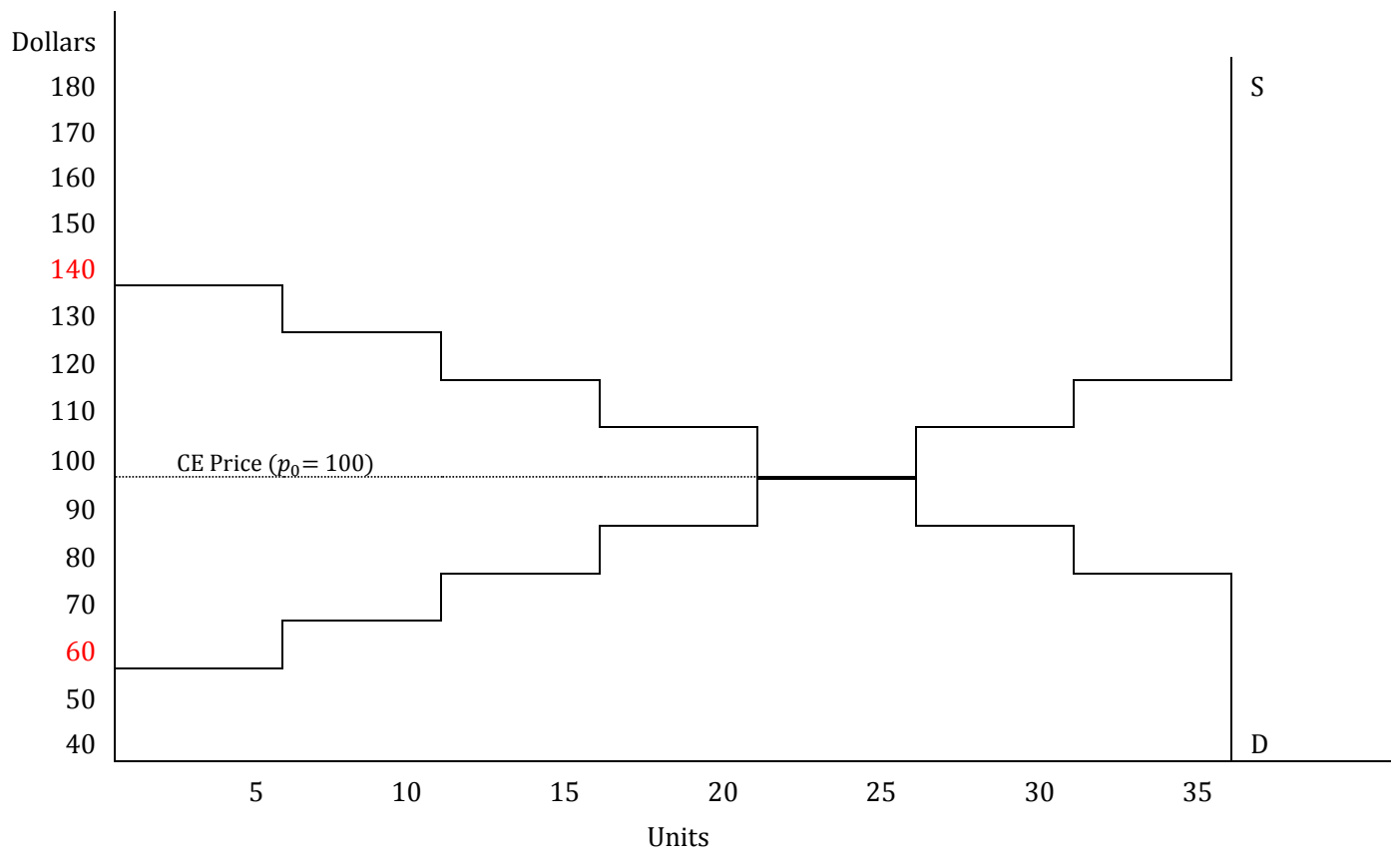

Figure 1: supply and demand curves for $x=0$

We linearly perturbed the inverse demand and inverse supply curves between periods. This prevented subjects from discovering the underlying equilibrium prices. For example, if $x=30$, all of the demand and supply steps in Figure 1 would be shifted up by 30, making the competitive equilibrium price 130. Table 2 below displays values of $x$, the random variable drawn for each trading period.

\begin{tabular}{|c|c|c|c|c|c|c|c|c|c|c|c|c|c|c|c|c|c|c|}
\hline Period & 1 & 2 & 3 & 4 & 5 & 6 & 7 & 8 & 9 & 10 & 11 & 12 & 13 & 14 & 15 & 16 & 17 & 18 \\
\hline$x$ & -30 & 50 & -40 & 50 & 0 & -40 & -10 & -20 & 40 & -20 & -50 & -50 & 40 & 20 & 10 & -20 & -30 & -50 \\
\hline
\end{tabular}

Table 2: values of $x$

Subjects participated in multiple trading periods of various treatments: 
Baseline: This is a nonstationary double auction with no fee structure exogenously imposed on subjects.

TF1/2 (Trading Fees - Treatment \#1/2): Both sides of each transaction are assessed an identical fee. The levels of net fee per transaction match those in the make and take fee treatments, which enables direct comparison between the treatments.

$\underline{\text { MT1/2/3 }}$ (Make \& Take Fees - Treatment \#1/2/3): A make and take fee structure is exogenously imposed on subjects. MT2 and MT3 increase the level of net fee relative to MT1. From MT1 to MT2, the make rebate is lowered. From MT1 to MT3, the take fee is increased. The fees for each treatment in our experiments are given in Table 3.

\begin{tabular}{|c|c|c|c|c|}
\hline Treatment & Trading Fee & Take Fee & Make Rebate & Net Fee \\
\hline B & 0 & 0 & 0 & 0 \\
\hline TF1 & 0.5 & 0 & 0 & 1 \\
\hline TF2 & 1 & 0 & 0 & 2 \\
\hline MT1 & 0 & 3 & 2 & 1 \\
\hline MT2 & 0 & 3 & 1 & 2 \\
\hline MT3 & 0 & 4 & 2 & 2 \\
\hline
\end{tabular}

Table 3: fee structure for all treatments

The fee levels that we selected for our experiments is similar to the fee structures in place on U.S. equity exchanges. As discussed earlier, the fees assessed by exchanges are on the order of 20 30 cents per hundred shares traded (or, $0.2-0.3$ cents per share). In our experiment, a take fee of 3 represents a fee of three U.S. cents (conversion rate $=\$ 0.01$ per experimental dollar earned). Thus, for purposes of generalizability, we assume that each share traded in our experiment reflects a block of 10 shares.

To illustrate the supply and demand schedules in MT, refer to Figure 2. Assume that in this market, all buyers are market makers and all sellers are market takers without loss of generality. Recall that a market making buyer $i$ is willing to post a price in the interval $\left[0, v_{i}+m\right]$. Thus, each step on the demand curve is shifted up by $m$. Similarly, a market taking seller $j$ is willing to post a price in the interval $\left[c_{j}+t, \infty\right]$. Accordingly, each step on the supply curve is shifted up by $t$. Figure 
2 plots the shifted demand and supply curves ( $\mathrm{D}^{\prime}$ and $\mathrm{S}^{\prime}$, respectively) and the original demand and supply curves (D and S). In D and S, the equilibrium price is 100 and the equilibrium quantity is contained in the interval $[20,25]$. D' and S' now intersect vertically, so the equilibrium price is contained in the interval $[100+m, 100+t]$ and the equilibrium quantity is 20 .

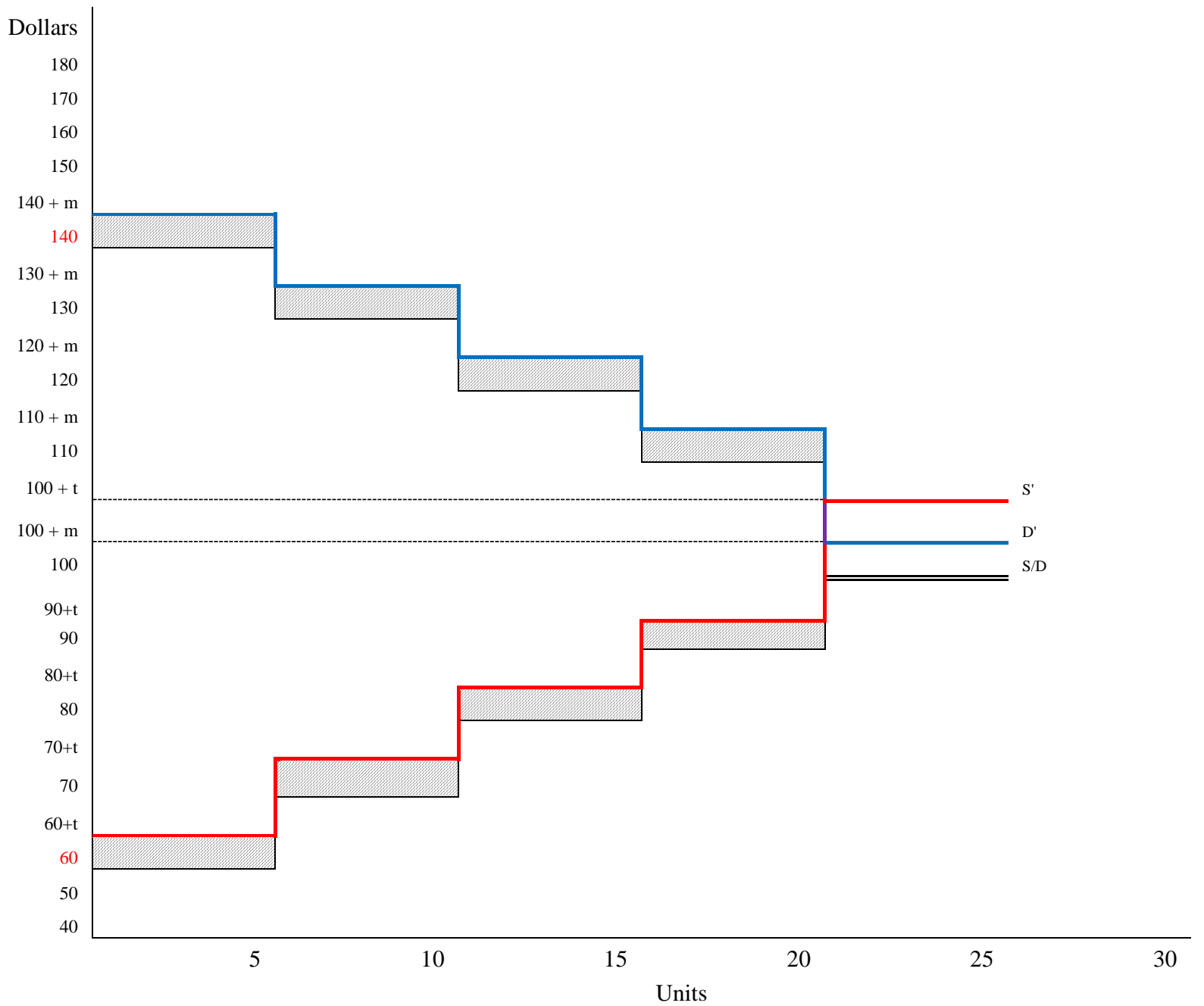

Figure 2: supply and demand curves for $x=0$ with MT

We used a crossover design that controlled for treatment order effects. Table 4a illustrates the crossover design that was used during the first twelve sessions. Data were collected from the grayed periods. Since there are three MT treatments (MT1, MT2 and MT3), we permuted the orderings so that each treatment was in each of the blocks twice across the 12 experiments.

\begin{tabular}{|c|c|c|c|c|c|c|c|c|c|c|c|c|c|c|c|c|c|c|}
\hline Period & 1 & 2 & 3 & 4 & 5 & 6 & 7 & 8 & 9 & 10 & 11 & 12 & 13 & 14 & 15 & 16 & 17 & 18 \\
\hline Treatment & B & B & B & MT & MT & MT & B & B & B & MT & MT & MT & B & B & B & MT & MT & MT \\
\hline
\end{tabular}


Table 4a: treatment order (MT \& B sessions)

Table $4 \mathrm{~b}$ illustrates the design of the remaining four sessions, where we implemented the relevant baseline case (TF1 and TF2). Again, data were collected from the grayed periods.

\begin{tabular}{|c|c|c|c|c|c|c|c|c|c|c|c|c|c|c|c|c|c|c|}
\hline Period & 1 & 2 & 3 & 4 & 5 & 6 & 7 & 8 & 9 & 10 & 11 & 12 & 13 & 14 & 15 & 16 & 17 & 18 \\
\hline Treatment & $\mathrm{B}$ & $\mathrm{B}$ & $\mathrm{B}$ & $\mathrm{TF}$ & $\mathrm{TF}$ & $\mathrm{TF}$ & $\mathrm{TF}$ & $\mathrm{TF}$ & $\mathrm{TF}$ & $\mathrm{B}$ & $\mathrm{B}$ & $\mathrm{B}$ & $\mathrm{TF}$ & $\mathrm{TF}$ & $\mathrm{TF}$ & $\mathrm{TF}$ & $\mathrm{TF}$ & $\mathrm{TF}$ \\
\hline
\end{tabular}

Table 5 summarizes our experimental design and subject earnings.

\begin{tabular}{|c|c|c|c|c|}
\hline Session & Subjects & Session & Treatment Order & Avg. Earnings \\
\hline $\mathbf{1}$ & 12 & MT & 123 & $\$ 29.93$ \\
\hline $\mathbf{2}$ & 12 & MT & 123 & $\$ 28.69$ \\
\hline $\mathbf{3}$ & 12 & MT & 132 & $\$ 28.22$ \\
\hline $\mathbf{4}$ & 12 & MT & 132 & $\$ 29.01$ \\
\hline $\mathbf{5}$ & 12 & MT & 213 & $\$ 28.40$ \\
\hline $\mathbf{6}$ & 12 & MT & 213 & $\$ 28.27$ \\
\hline $\mathbf{7}$ & 12 & MT & 231 & $\$ 27.87$ \\
\hline $\mathbf{8}$ & 12 & MT & 231 & $\$ 28.63$ \\
\hline $\mathbf{9}$ & 12 & MT & 312 & $\$ 28.14$ \\
\hline $\mathbf{1 0}$ & 12 & MT & 312 & $\$ 28.50$ \\
\hline $\mathbf{1 1}$ & 12 & MT & 321 & $\$ 28.52$ \\
\hline $\mathbf{1 2}$ & 12 & MT & 321 & $\$ 27.90$ \\
\hline $\mathbf{1 3}$ & 12 & TF & 12 & $\$ 28.76$ \\
\hline $\mathbf{1 4}$ & 12 & TF & 12 & $\$ 27.92$ \\
\hline $\mathbf{1 5}$ & 12 & TF & 21 & $\$ 28.82$ \\
\hline & 12 & TF & 21 & $\$ 28.79$ \\
\hline
\end{tabular}

Table 5: experimental results (by session)

The following section describes the methodology for each of the statistics captured during the sessions.

Book Depth: Book depth is the number of unique bids and asks in a system at a given point in time and will serve as a proxy for liquidity in the system. We calculate it as a time-weighted average of the number of unique active bids and asks. Mathematically, we can observe a sequence of $k$ transactions (bids, asks, and contracts) within each market period. Let $r=\left(r_{1}, r_{2}, \ldots, r_{k}\right)$ represent this sequence where $r_{1}$ represents the first bid or ask within a market period. Let $y=\left(y_{1}, y_{2}, \ldots, y_{k}\right)$ represent a sequence corresponding to $r$ where $y_{i}$ is a count of the bids and asks in the order book 
at $r_{i}$. Here is a simple example: $r=($ bid, bid, ask, contract, bid, ask). Thus, $y=(1,2,3,1,2,3)$. Finally, define $z=\left(z_{1}, z_{2}, \ldots, z_{n}\right)$ as a sequence of timestamps within a market period, where $z_{1}$ is the time at which $r_{1}$ was posted.

Thus, $z_{2}-z_{1}$ represents the time elapsed between $y_{2}$ and $y_{1}$. Book depth is calculated as follows within each period:

$$
d=\sum_{1}^{k} \frac{y_{i}\left(z_{i+1}-z_{i}\right)}{z_{k}}
$$

We also discuss trading volume in relation to book depth. We again use $n$ for the number of contracts formed per market period.

Bid-Ask Spread: Bid-Ask spread was calculated as a time-weighted average in each period: $\frac{\sum_{i=1}^{n} s_{i}\left(\frac{t_{i}}{T}\right)}{100+x}$ where $s_{i}$ is the bid-ask spread since the last bid, ask, or contract (this is undefined when no bid or ask is posted), $t_{i}$ is the time (in seconds) elapsed since the last bid, ask, or contract, $T$ is the duration of the market period (in seconds), $x$ is the value of the random variable drawn in each period, and $n$ is the number of contracts formed per market period. We calculate a true quoted spread, which is simply the difference between the best bid and best ask.

Efficiency: In each period, efficiency is calculated as $\frac{\text { Realized Surplus }}{\text { Theoretical Max Surplus }}=\frac{s_{R}}{S_{T}}=e$. Realized Surplus is the total value minus costs of trades made in the market. The Maximum Surplus is the maximum theoretical gains from exchange (values minus costs) in the system. This definition implies that we do not consider the exchange's gains from trade when calculating efficiency in periods with fees. Rather, we evaluate subject efficiency relative to best possible outcome to traders given the state of the environment. 


\section{Results \& Discussion}

Recall earlier that we parameterized our sessions to be able to make direct comparisons between MT and TF by setting the net fees equal between fee structures and sessions. This is illustrated in Table 6.

\begin{tabular}{|c|c|c|}
\hline Net Fee & MT Treatment & TF Treatment \\
\hline $\mathbf{1}$ & MT1 & TF1 \\
\hline $\mathbf{2}$ & MT2, MT3 ${ }^{5}$ & TF2 \\
\hline
\end{tabular}

Table 6: treatments (by net fee level)

\section{III.I Book Depth}

Our hypothesis for book depth were as follows:

1. Book depth will increase in the presence of make and take fees relative to trading fees and no fees because of the incentives (rebates) to monitor the market more closely.

2. Book depth will increase with the level of make rebates, holding the take fee constant.

\begin{tabular}{|c|cc|}
\hline Hypothesis & $\mathbf{H}_{\boldsymbol{o}}$ & $\mathbf{H}_{\boldsymbol{a}}$ \\
\hline 1 & $\mathrm{MT}=\sim \mathrm{MT}$ & $\mathrm{MT} \geq \sim \mathrm{MT}$ \\
\hline 2 & MT13 $=$ MT2 & MT13 $\geq$ MT2 \\
\hline & Table 7a: hypothesis (book depth) & \\
\hline
\end{tabular}

In MT, the average time-weighted book depth was 12.99. That is, there were 12.99 unique bids and asks in the order queue on average at each moment in continuous time. Relative to MT, we observed a decrease in book depth in TF to 10.72 and a decrease in book depth in B to 12.49. In MT, it appears that subjects employ rebate-capture strategies by continually updating their bids and

${ }^{5}$ For the remainder of the paper, we use the following conventions:

- $\quad \mathrm{MT} 13=\mathrm{MT} 1 \&$ MT3

- $\quad \mathrm{MT} 12=\mathrm{MT} 1 \& \mathrm{MT} 2$

- $\quad \mathrm{MT} 23=\mathrm{MT} 2 \& \mathrm{MT} 3$

- $\quad \mathrm{MT}=\mathrm{MT} 1, \mathrm{MT} 2, \& \mathrm{MT} 3$

- $\mathrm{TF}=\mathrm{TF} 1 \& \mathrm{TF} 2$

- $\quad \sim \mathrm{MT}=\mathrm{B} \& \mathrm{TF}$

- $\sim \mathrm{B}=\mathrm{MT} \& \mathrm{TF}$ 
asks by small amounts. Indeed, in the post-experiment questionnaires, subjects indicated a propensity to employ these strategies. For example, one subject wrote "You should not accept very many offers to sell to avoid trading fees, so it's worth it to just up their offer by one and put it on the board" in response to the question "Was your strategy different in periods with trading fees vs. periods without trading fees?" Table 7b reports summary statistics for each treatment.

\begin{tabular}{|c|c|c|c|c|c|}
\hline Treatment & $\mathbf{n}$ & Mean & Std. Dev. & Min & Max \\
\hline B & 27 & 12.49 & 2.49 & 7.27 & 18.10 \\
\hline MT1 & 12 & 12.73 & 2.54 & 8.74 & 17.42 \\
\hline MT2 & 12 & 12.88 & 2.26 & 9.54 & 16.19 \\
\hline MT3 & 12 & 13.36 & 2.69 & 9.00 & 17.35 \\
\hline MT12 & 24 & 13.04 & 2.58 & 8.74 & 17.42 \\
\hline MT (pooled) & 36 & 12.99 & 2.45 & 8.74 & 17.42 \\
\hline TF1 & 8 & 10.43 & 1.42 & 8.12 & 12.51 \\
\hline TF2 & 8 & 11.01 & 2.13 & 8.59 & 14.55 \\
\hline TF (pooled) & 16 & 10.72 & 1.77 & 8.12 & 14.55 \\
\hline$\sim$ MT & 43 & 11.83 & 2.39 & 7.27 & 18.10 \\
\hline & Table 7b: summary statistics (book depth) & \\
\hline
\end{tabular}

We first consider the difference in book depth between MT and $\sim$ MT (B \& TF). We find that book depth is highest in periods with make and take fees because of the additional incentives to monitor the market more closely in the form of make rebates. The increase in book depth was statistically significant at the 0.05 level. However, contrary to our hypothesis, we do not find a statistically significant increase in book depth when the incentives to monitor the market (within MT) are highest. However, despite the lack of statistical significance, the book depth observed in MT3 (the market periods with the highest take fees and make rebates) was the highest of any treatment in our sessions. Table 7c summarizes our statistical results.

\begin{tabular}{|c|c|c|c|c|}
\hline Result & $\mathbf{H}_{\boldsymbol{o}}$ & $\mathbf{H}_{\boldsymbol{a}}$ & $\mathbf{t}$ & $\mathbf{p}$ \\
\hline 1 & $\mathrm{MT}=\sim \mathrm{MT}$ & $\mathrm{MT} \geq \sim \mathrm{MT}$ & 2.1206 & 0.0187 \\
\hline 2 & $\mathrm{MT3}=\mathrm{MT12}$ & $\mathrm{MT3} \geq \mathrm{MT} 12$ & 0.6339 & 0.2652 \\
\hline
\end{tabular}




\section{III.II Efficiency}

We next turn to efficiency to determine if the presence of a fee structure affects subject welfare.

Recall our hypothesis:

1. Subject efficiency is not affected by the presence or absence of a fee structure when calculated relative to the maximum possible surplus subjects can extract in a given market period.

2. With fees, efficiency will be lower when the equilibrium price is lower.

\begin{tabular}{|c|cc|}
\hline Hypothesis & $\mathbf{H}_{\boldsymbol{o}}$ & $\mathbf{H}_{\boldsymbol{a}}$ \\
\hline 1 & $\mathrm{~B}=\sim \mathrm{B}$ & $\mathrm{B} \neq \sim \mathrm{B}$ \\
\hline 2 & \multicolumn{2}{|c|}{ Section III. IIB } \\
\hline
\end{tabular}

Table $8 \mathrm{~b}$ reports summary statistics (in percentages) for each treatment.

\begin{tabular}{|c|c|c|c|c|c|}
\hline Treatment & n & Mean & Std. Dev. & Min & Max \\
\hline B & 27 & 98.19 & 1.36 & 95.50 & 100 \\
\hline MT1 & 12 & 97.95 & 1.51 & 94.74 & 99.90 \\
\hline MT2 & 12 & 97.69 & 2.29 & 93.02 & 99.90 \\
\hline MT3 & 12 & 96.42 & 2.32 & 91.67 & 99.44 \\
\hline MT (pooled) & 36 & 97.35 & 2.12 & 91.67 & 99.90 \\
\hline TF1 & 8 & 96.93 & 2.75 & 92.81 & 99.80 \\
\hline TF2 & 8 & 97.92 & 1.30 & 95.73 & 99.79 \\
\hline TF (pooled) & 16 & 97.42 & 2.14 & 95.73 & 99.80 \\
\hline$\sim$ B & 52 & 97.37 & 2.11 & 91.67 & 99.90 \\
\hline
\end{tabular}

Table 8b: summary statistics (efficiency)

As shown in Appendix D, subject efficiency was high (>91\%) in our sessions. However, contrary to our hypothesis, we find that efficiency was lower in MT \& TF $(\sim \mathrm{B})$ relative to B. The decrease was statistically significant, but relatively unsubstantial (98.19\% to $97.37 \%)$.

\begin{tabular}{|c|c|c|c|c|}
\hline Result & $\mathbf{H}_{\boldsymbol{o}}$ & $\mathbf{H}_{\boldsymbol{a}}$ & $\mathbf{t}$ & $\mathbf{p}$ \\
\hline 1 & $\mathrm{~B}=\sim \mathrm{B}$ & $\mathrm{B} \neq \sim \mathrm{B}$ & 2.1206 & 0.0187 \\
\hline
\end{tabular}


Table 8c: results (efficiency)

We consider Hypothesis 2 later in this section. So far, we have observed that make and take fees induce market participants to place more non-marketable orders, which enables the exchange to provide more opportunities for others to trade. However, we observe what appears to be no relationship between book depth and efficiency, which was low in MT and TF despite high book depth in MT and low book depth in TF. We estimate the following regression to determine whether the presence of more orders necessarily improve aggregate trader welfare:

$$
\text { Efficiency }_{i}=\beta_{0}+\text { BookDepth }_{i}+\varepsilon_{i}
$$

where $i$ represents all MT and TF periods.

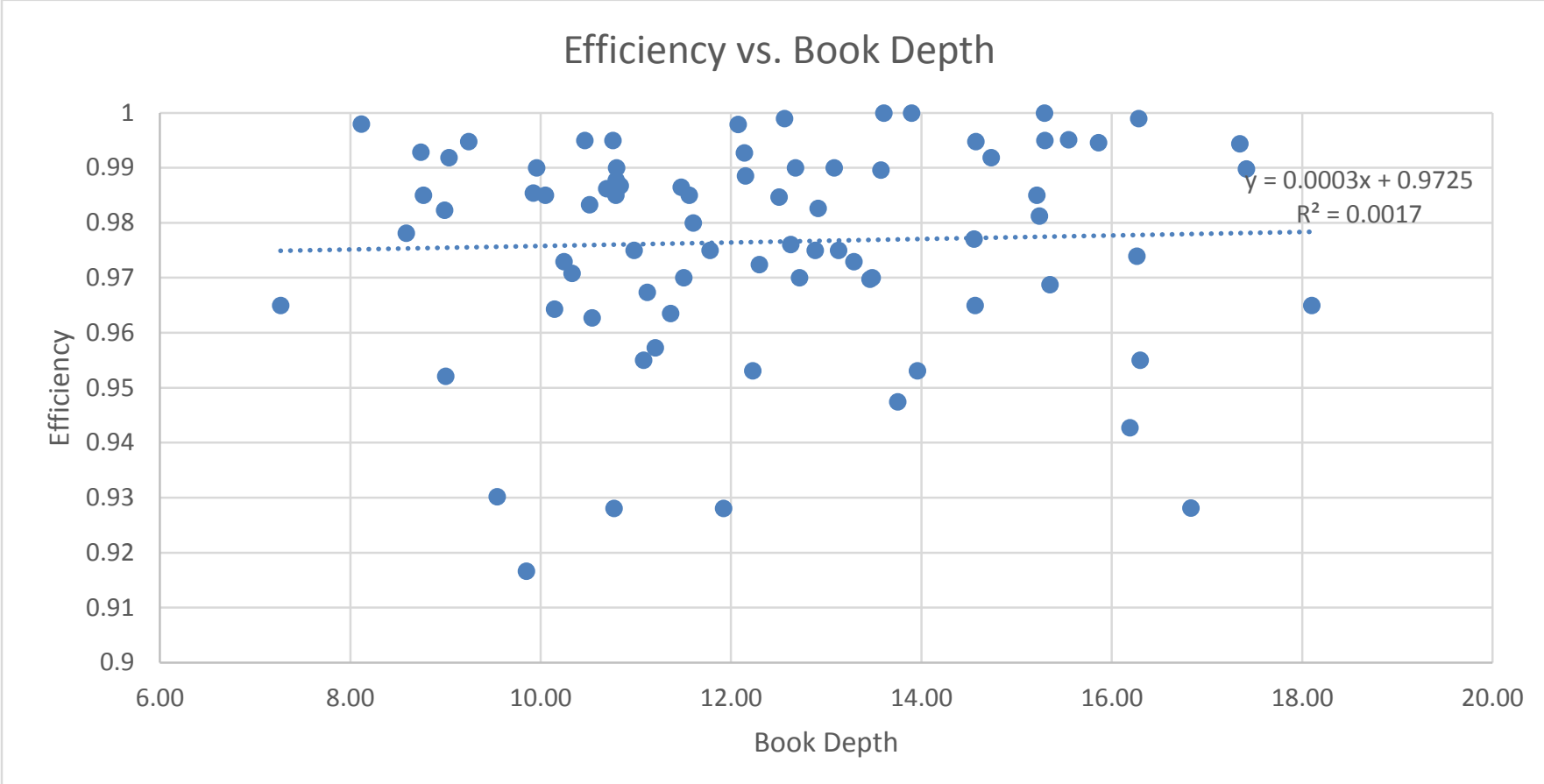

Figure 3: scatterplot of efficiency vs. book depth

It is clear from the regression in Figure 3 that there is no relationship between book depth and efficiency. That is, whatever rebate capture strategies subjects may have employed were ineffective at raising aggregate surplus. Providing additional opportunities to trade did not necessarily induce traders to make better trading decisions. Conversely, less opportunities to trade (in TF) led to less opportunities to trade profitably. We remain interested in uncovering why 
subject efficiency was lower in periods with fees. We consider trading volume (either under-trading or over-trading relative to the equilibrium prediction) as a possible cause of this efficiency decrease by estimating the following exponential regression:

$$
\text { Efficıency }_{i}=\beta_{0}+\text { TradıngVolume }_{i}{ }^{2}+\text { TradıngVolume }_{i}+\varepsilon_{i}
$$

where $i$ represents all MT and TF periods.

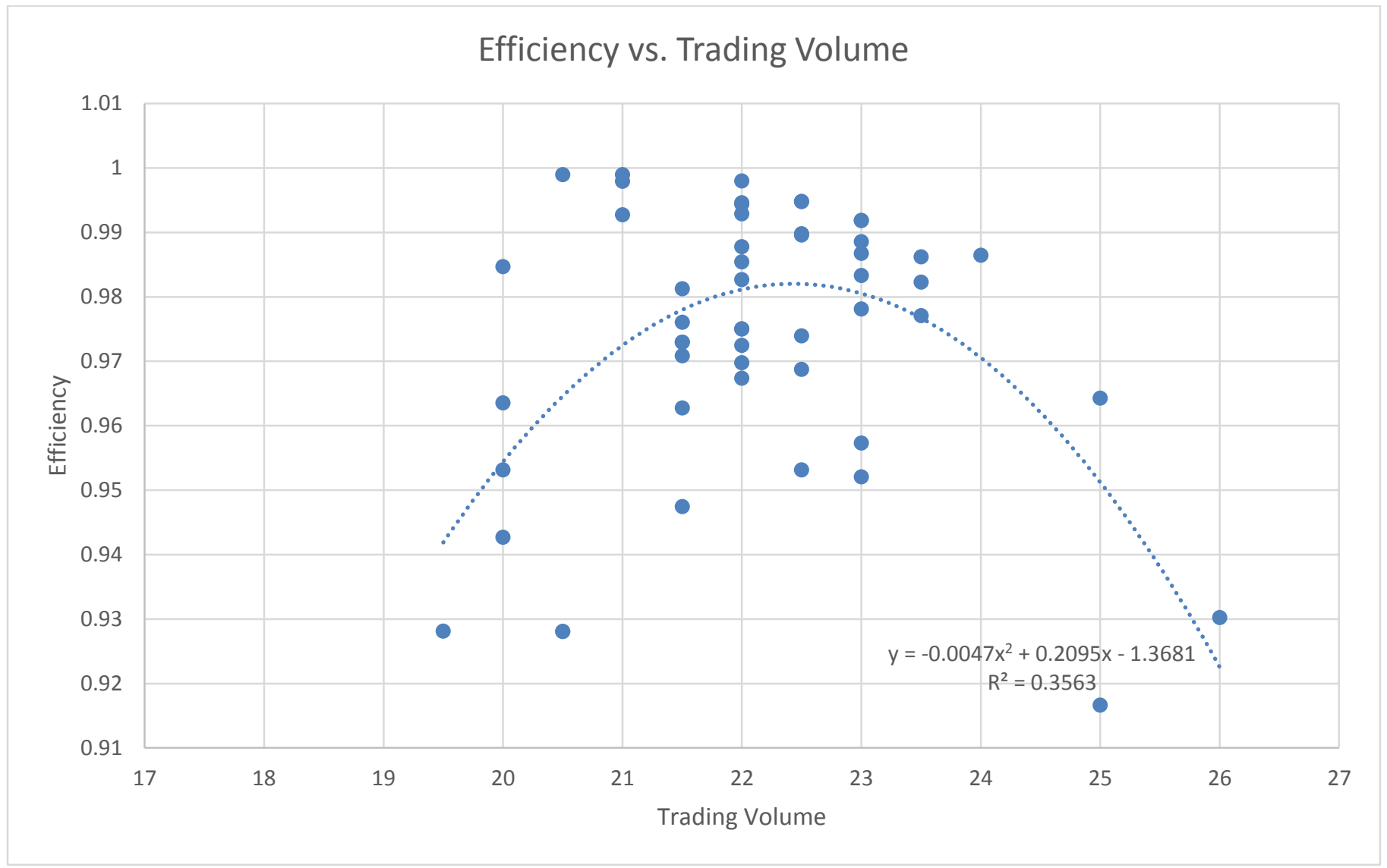

Figure 4: scatterplot of efficiency vs trading volume

We observe in Figure 4 that efficiency is lowest in periods with the most and the least trading. Recall that in both MT and TF, the equilibrium prediction for trading volume was 20 units per market period. The plot displays a striking amount of overtrading. It is clear that the periods with the highest efficiency were the ones in which subjects traded between 21 and 23 units. This represents overtrading of $1-3$ units per period, but it does appear that subjects were able to 
capture the majority of the profitable transactions that were available. The slight reduction from $100 \%$ efficiency was due to the presence of the unprofitable trades. The trades themselves were We report summary statistics for trading volume in Table 9

\begin{tabular}{|c|c|c|c|c|c|}
\hline Treatment & n & Mean & Std. Dev. & Min. & Max. \\
\hline MT1 & 12 & 22.000 & 0.603 & 21 & 23 \\
\hline MT2 & 12 & 22.292 & 1.514 & 20 & 26 \\
\hline MT3 & 12 & 21.917 & 1.621 & 19.5 & 25 \\
\hline TF1 & 8 & 22.000 & 1.732 & 20 & 25 \\
\hline TF2 & 8 & 22.500 & 0.926 & 21 & 23.5 \\
\hline
\end{tabular}

Table 9: summary statistics (trading volume)

These results are curious, as subjects were under no obligation to buy or sell any shares at a loss. One of two explanations is plausible.

1. The presence of a fee structure in a dynamic, quickly-evolving environment taxed subjects' cognitive loads, causing them to make unprofitable decisions.

2. Subjects viewed fees as a "cost of doing business" and paid little attention to them.

\section{III.II.B Level of Net Fee}

We conclude our discussion of efficiency by considering the effects of the level of net fee on trader welfare/efficiency. Make and take fees, like the trading fees they supplanted as the prevailing fee structure used by equity exchanges, are assessed based on trading volume without regard to share price. That is, investors pay identical fees whether they are buying 100 shares of a high price stock or a penny stock. Here, we take the equilibrium price $P^{*}$ (shown in Table 10) and divide by the level of net fee (either 1 or 2 ) to examine the relationship between gross efficiency (unadjusted for fees) and the magnitude of the fees relative to the predicted price. Recall that since we permutated the treatment order between sessions, the resulting measure will differ between sessions.

\begin{tabular}{|c|c|c|c|c|c|c|}
\hline Period & 5 & 6 & 11 & 12 & 17 & 18 \\
\hline$P^{*}$ & 100 & 60 & 50 & 50 & 120 & 110 \\
\hline
\end{tabular}

Table 10: equilibrium prices in each period 
For example, the equilibrium price in Period 12 is 50. Suppose the level of net fee in this period is equal to 2 (as in certain market periods in the MT2 and MT3 treatments). Then, the fee magnitude is equal to $1 / 25$ of the equilibrium price. If the equilibrium price were greater than 50 , the magnitude would be lower than $1 / 25$, and we may expect less of an effect of imposing fees on our dependent variables.

As shown in Figure 5, we find that efficiency is highest in market periods where the level of net fee is low relative to the equilibrium predicted price. The intuition for this relationship, as discussed in the introduction, is when quantity-based fees are assessed, the fees have the greatest effect on efficiency for shares with lower prices.

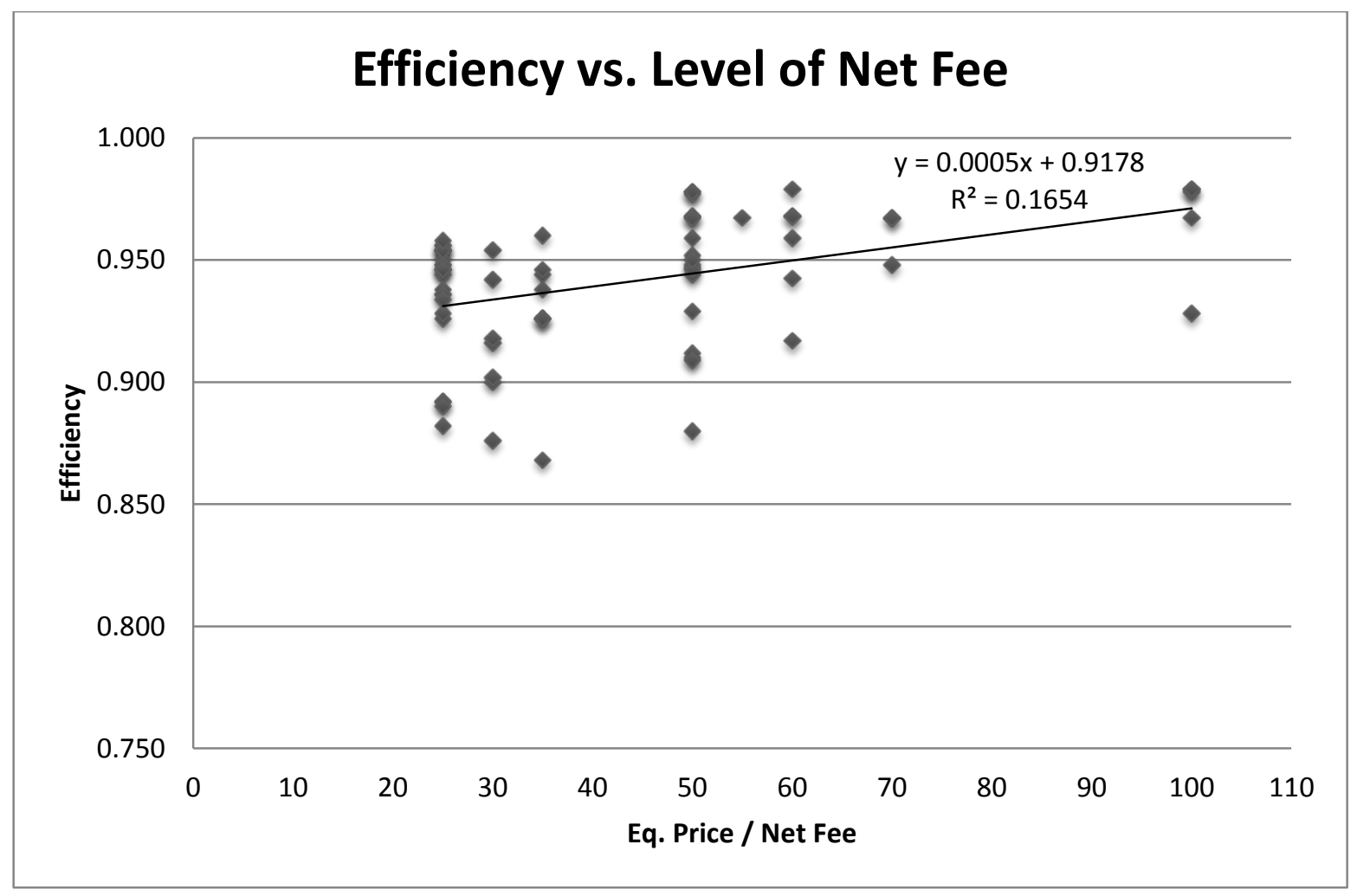

Figure 5: scatterplot of efficiency vs level of net fee

\section{III.IV Bid-Ask Spread}

As described earlier, we calculated bid-ask spread with respect to the equilibrium price (100) \pm a uniformly drawn constant within each market period. The quoted bid-ask spread is 
defined as the bid-ask spread exclusive of fees. The average quoted bid-ask spread was almost identical in MT and TF -0.165 and 0.164 , respectively. The quoted bid-ask spread increased in both cases relative to the baseline case of 0.157 . Recall that our hypothesis was non-directional in nature and our model was designed such that any treatment effects were endogenously determined - that is, the bid-ask spread should have been equivalent theoretically and our results confirm that intuition. Table 11a reports summary statistics for each treatment.

\begin{tabular}{|c|c|c|c|c|c|}
\hline Treatment & $\mathbf{n}$ & Mean & Std. Dev. & Min & Max \\
\hline B & 27 & .139 & .082 & .053 & .377 \\
\hline MT (pooled) & 36 & .165 & .057 & .035 & .280 \\
\hline TF (pooled) & 16 & .164 & .091 & .066 & .404 \\
\hline
\end{tabular}

A one-way ANOVA test $\left(H_{0}: \mu_{B}=\mu_{M T}=\mu_{T F} H_{A}: H_{0}\right.$ false) confirms that there is no statistically significant effect on the quoted-bid ask spread between treatments. $(F=1.07 p=$ 0.349). This confirms the empirical conclusion of Malinova and Park (2013) - recall that they examined a proprietary data set from a 2005 trial period on the Toronto Stock Exchange (TSX) and found that under a make and take fee regime, the quoted spreads did not change - and Kalcheva et al. (2014) who analyzed a larger sample of all registered equity exchanges from 2008 - 2010 and were unable to document a significant relationship between bid-ask spread and make and take fees. Next, we consider whether the allocation of net fee between maker and taker has an effect (See Table 11b).

\begin{tabular}{|c|c|c|c|c|c|}
\hline Treatment & $\mathbf{n}$ & Mean & Std. Dev. & Min & Max \\
\hline MT1 & 12 & .169 & .043 & .109 & .246 \\
\hline MT2 & 12 & .168 & .063 & .070 & .280 \\
\hline MT3 & 12 & .159 & .066 & .035 & .269 \\
\hline
\end{tabular}

Table 11b: summary statistics for quoted bid-ask spread (MT treatments)

We again fail to reject the null hypothesis $\left(H_{0}: \mu_{M T 2}=\mu_{M T 3}=\mu_{M T 1} H_{A}: \mu_{M T 2}=\mu_{M T 3}>\right.$ $\left.\mu_{M T 1}\right)$ that there is a statistically significant difference between MT2 and MT3 $(t=0.3511 p=$ 0.7236). The empirical conclusion from Colliard and Foucualt (2012) - that is, the quoted bid-ask 
spread can increase or decrease when the net fee is reduced, depending on whether the reduction in net fee is achieved by raising the make rebate - this causes a decrease - or by lowering the take fee - this causes an increase - is partially true here. Although we increased the level of net fee in our experiments in MT2 and MT3 relative to MT1, we would expect to see an increase in the quoted bidask spread upon lowering the make rebate and a decrease in the quoted bid-ask spread upon raising the take fee. We observed a slight decrease in the quoted bid-ask spread in MT3 (net fee $=$ 2) relative to MT1 (net fee $=1$ ), but there was no change in the quoted bid-ask spread in MT2 relative to MT1.

\section{Conclusion}

This paper investigated the effects of imposing an exogenous make and take fee structure on a nonstationary double auction model in an experimental setting. We compared the effects of make and take fees relative to a model in which trading fees were assessed to both sides of a transaction equally and a baseline case in which fees were absent. We examined trading volume and proxy measures of market quality and liquidity - efficiency, bid-ask spread, and book depth. There have been very few empirical studies of make and take fees given their recent widespread implementation. The results from the empirical literature were mixed - for example, two of the papers demonstrated opposite effects of make and take fees on the bid-ask spread. In addition, the strength of our paper is the controlled and randomized setting and elimination of some of the noise of the empirical data.

We observe that the presence of make and take fees induces subjects to place more orders, but this increase does not map into better trading decisions. Efficiency was lower in the presence of fees (both trading fees and make and take fees) which was caused by overtrading - the fees may have been too negligible for subjects to internalize their effects fully. Recall from our discussion of the magnitude of fees that for a share that is priced at $\$ 1.50$, the liquidity demander would pay a 
take fee that represents only $0.002 \%$ of the share price. For a share priced at $\$ 50$, the percentage drops to an infinitesimally low $0.00006 \%$. These results illustrate that make and take fees are likely to affect only institutional traders and brokers while the individual investor will likely continue to remain unaware of their presence.

In future research, we plan to extend the model developed in this paper and create an environment in which subjects assume one of three roles - buyers, sellers, and fee setters. This research will feature multiple markets operating simultaneously and have fee setters who will act as an equity exchange. This will enable us to directly observe the effects of changes in the level of fees in a controlled setting and produce an equilibrium prediction for the optimal level of net fee from the exchanges' perspective. Further, we can introduce brokers into the model to highlight the agency problem described in the empirical literature. 


\section{Bibliography}

Angel, James J., Lawrence E. Harris, and Chester S. Spatt. "Equity trading in the 21st century." The Quarterly Journal of Finance 1.01 (2011): 1-53.

Battalio, Robert, Shane A. Corwin, and Robert Jennings. "Can Brokers Have it all? On the Relation between Make Take Fees \& Limit Order Execution Quality." On the Relation between Make Take Fees \& Limit Order Execution Quality (December 13, 2013) (2013).

Battalio, Robert, Andriy Shkilko, and Robert Van Ness, 2011, To pay or be paid? The impact of taker fees and order flow inducements on trading costs in U.S. options markets, Working Paper Cardella, Laura, Jia Hao, and Ivalina Kalcheva. "Make and Take Fees in the US Equity Market." Working Paper (2014).

Colliard, Jean-Edouard, and Thierry Foucault. "Trading fees and efficiency in limit order markets." Review of Financial Studies 25.11 (2012): 3389-3421.

DiFotus, Demetrius. "Study Maker-Taker Trading Rebates, SECs Aguilar Says." 4/3/14. $<$ http://blogs.barrons.com/focusonfunds/2014/04/03/study-maker-taker-trading-rebates-secsaguilar-says $/ \bmod =$ BOLBlog $>$

Foucault, Thierry. "Pricing Liquidity in Electronic Markets." Foresight Driver Review

Foucault, Thierry, Ohad Kadan, and Eugene Kandel. "Liquidity cycles and make/take fees in electronic markets." The Journal of Finance 68.1 (2013): 299-341.

Gjerstad, Steven, and John Dickhaut. "Price formation in double auctions." Games and economic behavior 22.1 (1998): 1-29.

Harris, Larry, 2013, Maker-taker pricing effects on market quotations, Working paper.

Lynch, Sarah. "NYSE official calls for ending 'maker-taker' pricing structure." 6/17/14. $<$ http://www.reuters.com/article/2014/06/17/senate-hearing-marketsidUSL2N0OY0I520140617>

Malinova, Katya, and Andreas Park. "Subsidizing liquidity: The impact of make/take fees on market quality." November 23 (2011): 2011.

McCabe, Kevin A., Stephen J. Rassenti, and Vernon L. Smith. "Designing call auction institutions: is double Dutch the best?." The Economic Journal (1992): 9-23.

NYSE Arca Equities, Inc. "Schedule of Fees and Charges for Exchange Services." Last updated September 2014

<https://www.nyse.com/publicdocs/nyse/markets/nyse-arca/NYSE_Arca_Marketplace_Fees.pdf> 
O'Hara, Maureen. "High frequency market microstructure." Journal of Financial Economics 116 (2015): 257-270.

Securities and Exchange Commission Division of Trading and Markets. "Memorandum: MakerTaker Fees on Equity Exchanges." October 2015.

$<$ https://www.sec.gov/spotlight/emsac/memo-maker-taker-fees-on-equities-exchanges.pdf.

Securities and Exchange Commission. "Best Execution Guidelines" October 2015.

$<$ https://www.sec.gov/spotlight/emsac/memo-maker-taker-fees-on-equities-exchanges.pdf. 


\section{Appendix B - Subject Interface (buyer)}

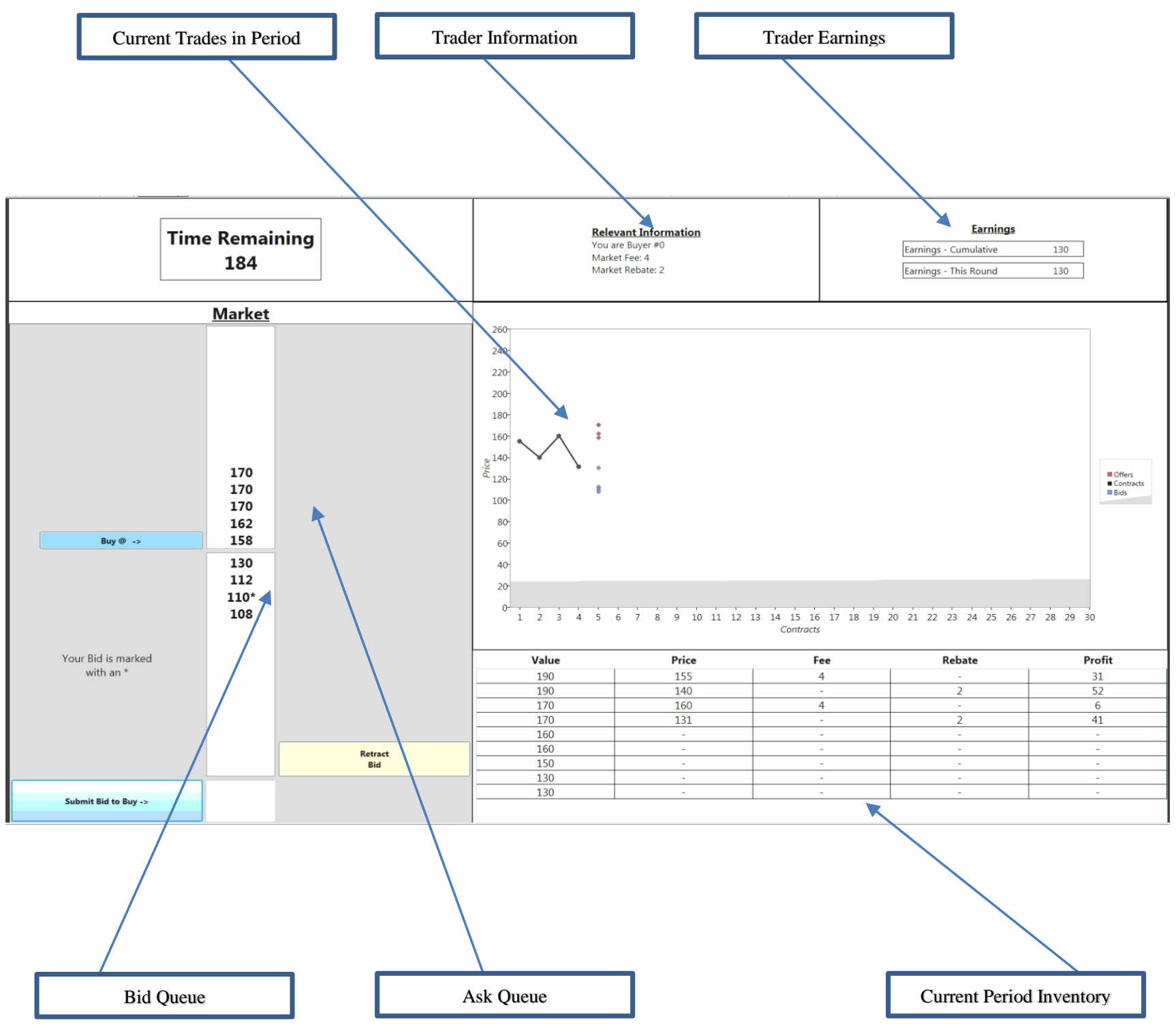




\section{Appendix C - Subject Instructions (buyer)}

Note: While completing the instructions, subjects were asked to perform tasks to demonstrate that they understood the experimental procedures (i.e. enter a bid). In the post-experiment questionnaire given to all subjects, the vast majority of subjects indicated that the instructions were clear. Seller instructions are very similar and are available from the author upon request.

\section{Introduction}

If you have any questions during the instructions or difficulties that arise after the experiment has begun, raise your hand and someone will assist you.

The experiment will consist of several 3-minute trading periods. Some of the participants in this room are buyers and some are sellers. For the duration of the experiment, you will be assigned to the role of buyer. Your role will not change between periods.

\section{Buyer Basics}

You will be given values (in Experimental Dollars) for one or more shares in each period in the holdings table displayed on the bottom right corner of the screen. You will attempt to purchase shares by placing bids to buy or accepting sellers' offers to sell.

To place a bid, enter the price at which you are willing to buy a share and click the 'Submit Bid to Buy' button. Your bid will be listed in the bid queue and will be marked with an asterisk.

Try this now. Type 100 into the box next to the 'Submit Bid to Buy' button and click the button. Your bid is now listed in the market along with another bid from another buyer for 110 .

If a seller accepts your bid, a contract is formed.

You may retract your bid at any time by selecting your bid in the bid queue and clicking the 'Retract Bid' button, as long as yours is not the standing bid (the highest price currently posted by the buyers).

Try this now. Select your bid of 100 by clicking the bid in the bid queue and press the 'Retract Bid' button.

There are two ways to accept the standing offer (the lowest price currently posted by the sellers):

1. Click the 'Buy@' button.

2. Place a bid that is higher than the standing offer.

In both cases, a contract will be immediately formed at the standing offer price. Contracts are formed in order from highest value to lowest value.

Try this now. Click the 'Buy@' button to observe the changes to your holdings table. You bought a share that you valued at 170 at a price of 120 for a profit of 50 . 
You cannot place more bids in the bid queue than you have remaining share values for. As you can see, you started with four share values in your holdings table. You bought one share, so you can now place up to three bids.

You may place bids at any time. Bids must be made in whole numbers (no decimals or fractions).

\section{Trading Mechanics}

In some trading periods, you will either be assessed a fee or receive a rebate upon contract formation. You will be assessed a fee if you accept the standing offer by clicking the 'Buy@' button or by placing a bid that is higher than the standing offer. In either case, a contract will be immediately formed at the standing offer price.

Try this now. Click the 'Buy@' button to observe the changes to your holdings table. You bought a share that you valued at 170 at a price of 120, but you were assessed a fee of 4 for a profit of 46 .

You will receive a rebate if you enter a bid that is lower than the standing offer and wait for a seller to accept your bid. If no seller accepts your bid, you will not receive a rebate.

Try this now. Type 100 into the box next to the 'Submit Bid to Buy' button and click the button. Your bid is now listed in the market along with another bid from another buyer for 90 .

On the next page, you will observe what happens when a seller accepts your bid.

Your holdings table has been updated as a seller accepted your bid of 100 . You bought a share that you had valued at 150 at a price of 100 , but you received a rebate of 2 for a profit of 52 .

You received a rebate since you entered a bid that was lower than the standing offer and waited for a seller to accept it.

\section{Calculating Your Earnings}

You will earn \$1 U.S. Dollar for every 100 Experimental Dollars that you earn during the experiment.

Your earnings in each period are independent and do not carry over into the next period. Your earnings for the experiment will be the sum of your earnings from each market period.

If you do not execute a trade in the period, you are guaranteed to earn zero profit. However, it is possible to earn negative profit if you do not trade wisely.

Your profit for each contract is given by the following formula:

$$
(\text { Value }- \text { Contract Price })-\text { Fee }+ \text { Rebate }=\text { Profit }
$$

Example One: You have a value of 50 for one share. The standing offer in the market is 40 . You accept the standing offer. You would be assessed a fee, which we will assume to be 5 for this example. Your profit for this contract is:

$$
\begin{aligned}
& (50-40)-5=5 \\
& (\text { Value }- \text { Contract Price })+\text { Rebate }=\text { Profit }
\end{aligned}
$$


Example Two: You have a value of 100 for one share. The standing offer in the market is 110 . You place a bid in the market for 97. A seller later accepts your bid. You will receive a rebate, which we will assume to be 5 in this example. Your profit for this contract is:

$$
\begin{aligned}
& (100-97)+5=8 \\
& (\text { Value }- \text { Contract Price })+\text { Rebate }=\text { Profit }
\end{aligned}
$$

As you have observed, the profit calculations are done for you in the holdings table once you form a contract.

At the top of your screen, the following information is provided in the 'Relevant Information' box;

- $\quad$ Buyer ID \#

- Market Fee \& Rebate

Your earnings for the experiment are displayed on the top right corner of the screen. This information is updated at the end of each trading period.

You have completed the instructions. The experiment will begin once all participants have completed the instructions. You may review the instructions now by using the navigational buttons at the bottom of the screen. Printed copies of the instructions should be available at your computer terminal. Once you are ready, click the Start button to proceed.

As a reminder, if you have any questions or difficulties that arise after the experiment has begun, raise your hand and someone will assist you.

\section{Appendix D - Subject Efficiency}




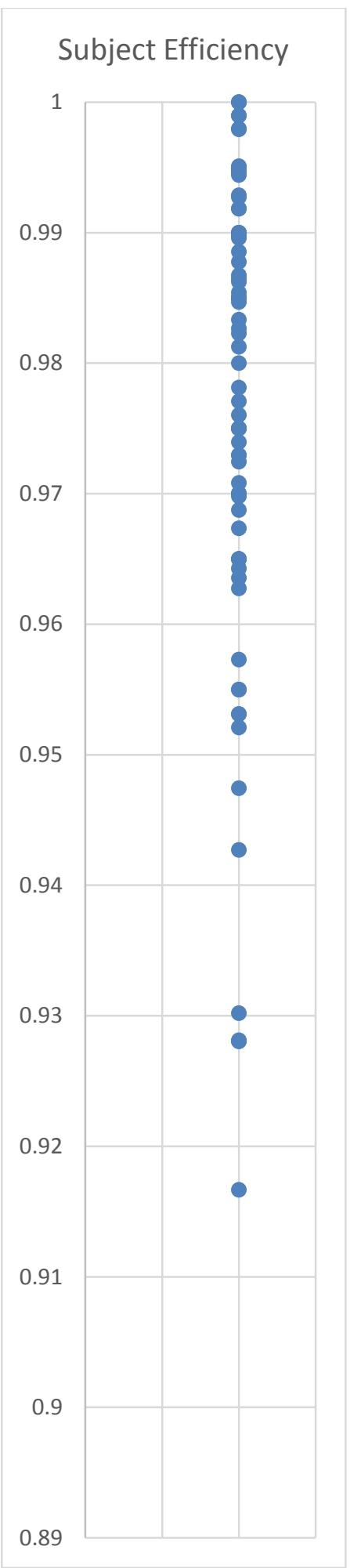

